\title{
KEES: A PRACTICAL ICT SOLUTION FOR RURAL AREAS
}

\author{
Xiaoye Dai ${ }^{1}$, Sabin Tabirca ${ }^{2}$, Eamon Lenihan ${ }^{3}$ \\ ${ }^{1}$ Corresponding author, Address: Room 223, O'Rahilly Building, Centre for Sustainable \\ Livelihoods, University College Cork, Ireland. Tel: +353214903548 Fax: +35321490 \\ 3540 Email:x.dai@cs.ucc.ie \\ ${ }^{2}$ Department of Computer Science, University College Cork, Ireland \\ ${ }^{3}$ Centre for Sustainable Livelihoods, University College Cork, Ireland
}

Abstract: This paper introduces a practical e-learning system, identified as Knowledge Exchange E-learning System (abbr. KEES), for knowledge distribution in rural areas. Particularly, this paper is about providing a virtual teaching and learning environment for small holders in agriculture in those rural areas. E-learning is increasingly influencing the agricultural education (information and knowledge learning) in all forms and the current e-learning in agricultural education appears in informal and formal methods in many developed countries and some developing areas such as Asian Pacific regions. KEES is a solution to provide education services including other services of information distribution and knowledge sharing to local farmers, local institutes or local collection of farmers. The design of KEES is made to meet the needs of knowledge capacity building, experience sharing, skill upgrading, and information exchanging in agriculture for different conditions in rural areas. The system allows the online lecture/training materials to be distributed simultaneously with all multimedia resources through different file formats across different platforms. The teaching/training content can be contextless and broad, allowing for greater participation by more small holders, commercial farmers, extension workers, agriculturists, educators, and other agriculture-related experts. The relative inconsistency in content gives farmers more localised and useful knowledge. The framework of KEES has been designed to be a three-tier architecture logic workflow, which can configure the progressive approach for KEES to pass on and respond to different requests/communications between the client side and the server.

Keywords: e-learning, multimedia synchronisation, knowledge dissemination, video

Please use the following format when citing this chapter:

Dai, X., Tabirca, S. and Lenihan, E., 2009, in IFIP International Federation for Information Processing, Volume 295, Computer and Computing Technologies in Agriculture II, Volume 3, eds. D. Li, Z. Chunjiang, (Boston: Springer), pp. 1817-1824. 


\section{INTRODUCTION}

Knowledge - and related information, skills, technologies, and attitudes will play a key role in the sustainable intensification of agriculture and success for rural development investment (Alex, 2002). However, the dissemination of knowledge in rural areas is not easy. Low level of education hampers the adoption of new technologies, farming skills and innovations. The literacy rate is usually low in these under-served areas and it is a crucial problem for farmers to learn and absorb new knowledge. Somehow, farmers are reluctant to accept new development unless it is the fact that the development would bring them more benefits when compared with their traditional practices.

Agricultural knowledge is often difficult to reach local farmers. The agricultural knowledge is often protected by the interests of chemical and seed manufacturers. As for marketing information, it is always cut off partially or even fully by the middle-men.

Colleges and institutes are the main forces for agricultural skills upgrading and innovations. Research students, fellows and lecturers can be the experts in farming fields. They pass over many agricultural skills, new research and development results, advanced technologies, and even diagnose some issues. However, the cost of field trips and the amount of time required are enormous.

The traditional means of passing on agricultural knowledge and skills from one generation to the other and/or among community members is becoming less effective. This is a result of several factors, such as fewer experts in rural areas, agricultural innovations are increasingly coming from outside the community, fewer traditional courses are being offered, and much information is time-sensitive and/or needed quickly (Agriculture and Agri-Food Canada, 2003). To solve these problems, it requires that an online agricultural education should provide a powerful means of overcoming these constraints and allow the individual student/learner to obtain up-to-date information by clicking their mouse.

When comparing the global non-agriculture e-learning trends versus global agriculture e-learning trends, report shows that "e-learning in Canadian, European, American and Australian agriculture falls significantly behind the current adoption rates seen in non-agriculture sectors." and "each of these countries are linking learning to marketable skills and selling etraining programme for specific agricultural training purposes." (Berge \& Leary, 2006)

The introduction of ICT into rural areas could be a possible solution for achieving the improvement of farmers' agricultural knowledge. However, it is more practical to develop a compatible online platform for the entire rural areas, including those in developed and developing countries or regions. 
Bearing this practical solution design in mind, researches are driven to find out a suitable system for farmers participatory learning.

\section{METHODOLOGY}

The research work is divided into two stages. The first stage was to collect requirements from agricultural educators and agriculture-related workers. It began with field trips selected in agricultural oriented countries such as Ghana and China. The main method of collecting information and data requirements is to interview agricultural educators in colleges and institutes, such as CARD centre (The Center for Agricultural and Rural Development) in Zhejiang University, and also some agriculture-related workers or researchers in agricultural research organisations, such as members of FARA (Forum for Agricultural Research in Africa). Through interviewing these experts in agriculture and agricultural education, it was found that users require a low-cost and easy-to-manage system.

Case studies proved that the constrains imposed due to lack of infrastructural facilities for the local farmers are the determinant factors for applying the special techniques needed in rural areas. However, the infrastructural conditions vary in different rural areas, and the research should find out the benchmark for grouping the rural areas generally. Based on rural area infrastructure situation, those developing areas could be divided into two experimental levels: mature level and beginning level. Regions or areas in mature level are usually equipped with TV, telephone or even Wi-Fi Internet connection. Those in beginning level are worse hit in facilities. They probably do not have TVs and/or telephones in the whole village nor the neighbouring villages. In this case, the difference in system dissemination should also be taken care of. DVD-based hard-copy dissemination is a supplementary to the Internet-based distribution in the newly developed system. It broadens the accessibility of the online courses, and also reduces costs to a realistic level.

The second stage was to develop a compatible system to meet the requirements of the agricultural educators and workers. During the research period, the designed system was tested at every milestone in rural areas in Ghana, Bosnia and Herzegovina, Czech Republic and China for its feasibility and robustness as well as for evaluation purposes. Questionnaires were carried out by agricultural educators and other agriculture-related researchers or workers in order to get feedback and comments to improve the system at each developing stage. 


\section{THE CHARACTERISTICS OF VIDEO CONTENT}

The characteristic of video content is a special issue to be addressed in this research. Here, farmers are the research target objects, they are various in their educational background, but the video based approach will help users to access the needed agricultural knowledge freely. The teaching or training content made in video format is a new, but efficient way of acquiring agricultural knowledge for most farmers regardless their educational background. After all, they are going to adopt a new practice instead of replacing their conventional operations completely. However, different areas have their localised situations and knowledge demanding. Farmers are also difficult to engage with during their leisure time. Therefore, the system should allow the video content to be simple, diverse and flexible. Video presenters should avoid using any terminology or jargons so as to make the content easy to understand while the topics could be various. Due to the informal community-based study in rural areas, the video content should be contextless and irrelevant to each other; this is to ensure farmers participation and also allow greater participation by other entities such as commercial farmers, extension workers, agriculturists, educators and other agriculture-related experts.

\section{TECHNICIAL DESIGN}

Knowledge Exchange E-learning System (abbr. KEES) is designed based on a three-tier structure (see Figure 1). The first layer on the left side is composed of HTML and SMIL files. They form simple and easy to control interfaces for system clients to use. Clients make requests and get feedback from SMIL embedded HTML pages. The middle layer is a client server comprised of Java and XML files. On this server, requests from client side are preceded and all the resources will be located or pointed to the physical links through XML file to the Streaming server. The third layer is the streaming server where all the educational resources are physically stored.

The design of the three-tier architecture work flow through the entire system is for the purpose of separating users from the complicated back end coding, and help them visualise their final production of multimedia synchronised presentations. The process improves the system's usability and also enhances the efficiency of content management characteristic of KEES.

Experts and agriculturists are intermediary users at one client side, but system remote users are the other main users which consist of local farmers, agricultural educators and researchers or local communities. Thus the topic raised by the intermediary users would be distributed and responded to. 
KEES works as a common platform for the two different levels of users by connecting their communication. (See Figure 2)

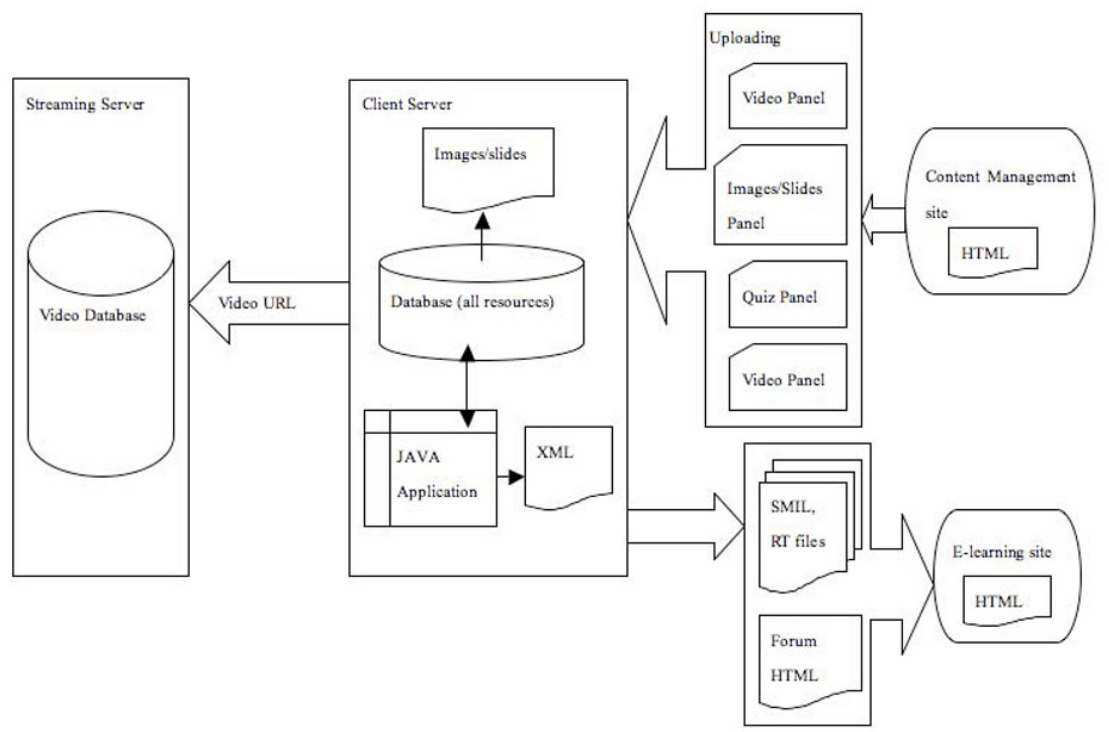

Figure 1 Three-tier Architecture Logic Workflow (Source: Xiaoye Dai, 2006)

As there are two level users in this system, KEES is designed with two interfaces for different users. KEES is focusing on simplifying the IT knowledge requirements of the educational content preparation for intermediary users and allows them take full advantage of all multimedia resources and distribute their presentations online.

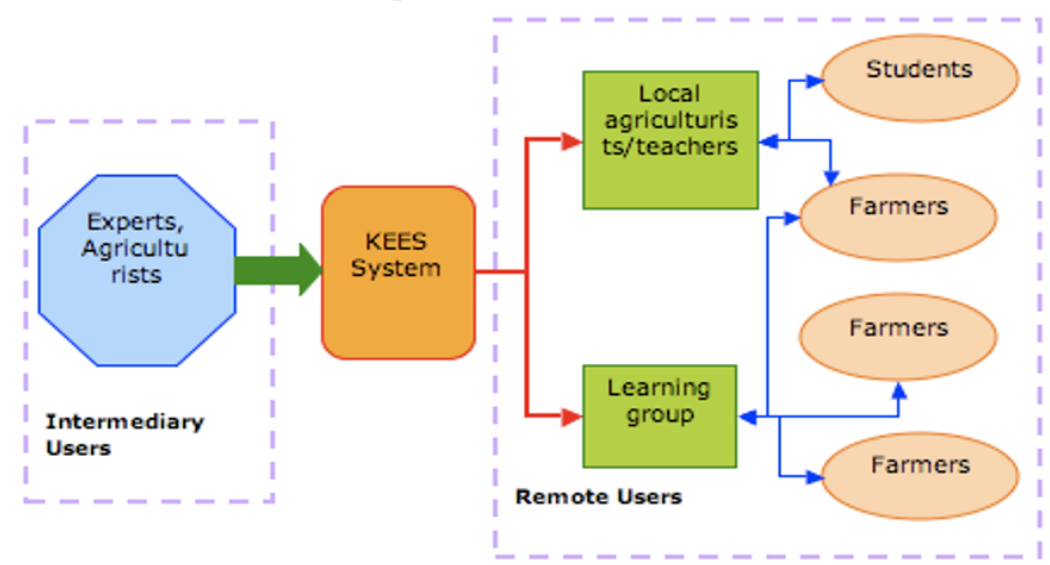

Figure 2 KEES user distribution diagram (Source: Xiaoye Dai, 2006) 
For the intermediary users, they would use Java Assisted SMIL (abbr. JAS) interface to deal with the video editing and teaching content synchronisation. JAS is programmed to be executed as a presentation-producing factory. To edit/produce a multimedia presentation requires all basic functions for editing videos and other additional features for generating the streaming files (see Figure 3).

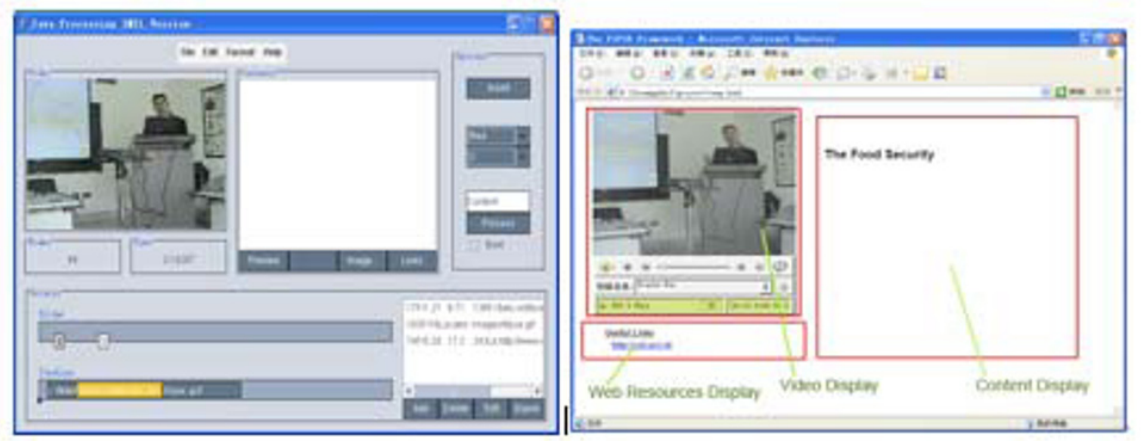

Figure 3 JAS interface and its Real Time based output layout (Source Xiaoye Dai, 2005)

JAS interface allow users to load video clips and synchronise text content, images and PowerPoint slides afterwards. External web resources can also be edited as URLs embedded into the synchronized outputs. Therefore, JAS takes the responsibilities of supplying end users options for editing and preparing the video for synchronisation performance.

For most remote users, the outputs are formatted as shown in Figure 3. Some computers or streaming servers might not be equipped with Real Time player so that another possible way to guarantee the distribution is to develop the other layout for Quick Time player (see Figure 4).

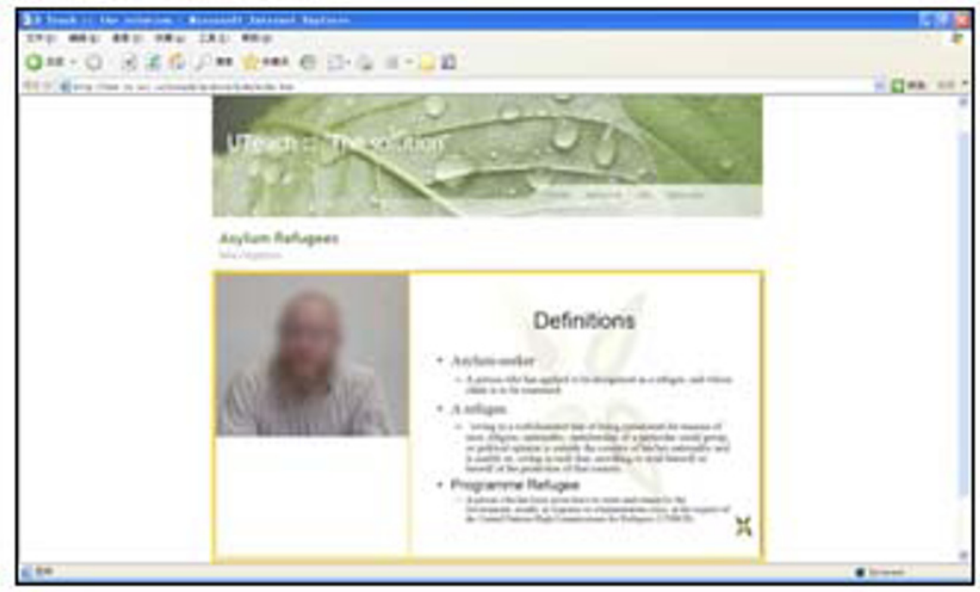

Figure 4 Quick time based layout (Source: Xiaoye Dai, 2006) 


\section{DISSEMINATION}

Consequent upon infrastructural conditions, mature level areas will have access to connect to the website to access the online video archives. Users in those relatively advanced areas can watch the training course or knowledge information via the web pages as shown in Figure 3 and Figure 4. As for the beginning level areas, TVs and DVDs should be equipped in some selected collecting points for local farmers to gain access to the information. TV and DVD equipments could be shared within several villages by providing gathering places to play the video. With funds, each village could be equipped with one set of TV and DVD to repeat playing the video so that farmers would have more optional time to join the participant learning process.

\section{CONCLUSION}

In farming communities, literacy rate is substantially low. There is no doubt that teaching from books and leaflets would meet certain difficulties. The benefits of traditional learning would be long-term and intangible rewards to local farmers. However, farmers rely on their farming products for living, and the short-term profits to improve their life would be the only motivation for them to keep learning after their daily agricultural activities. Watching and listening to the demonstration is a faster approach for them to acquire knowledge. Video creation tends to be the way forward for those particular participant learners, which is less expensive compared to other types of media.

KEES builds up and improves the ICT roles of communication between the experts and the local farmers. Through applying different teaching and learning materials, farmers' trust and confidence in learning from virtual environment will be formed and enhanced.

KEES specifies the template of multimedia presentation outputs and the regulation of synchronising multimedia educational resources. Under certain infrastructure conditions, KEES has been proved to be capable of improving access to agricultural education, helping in knowledge capacity building, enabling educational information distribution, skill upgrade, information exchange and offering a platform to exchange teaching and learning experience. 


\section{REFERENCES}

Agriculture and Agri-Food Canada. (2003, August 29). An overview of e-Learning in Canadian agriculture and Agri-business. Retrieved from:

Alex G, Zijp W, Byerlee D, et al. 2002. Rural extension and advisory services: new directions. Rural Development Strategy Background Paper No. 9. Washington, D.C. (USA): Agriculture and Rural Development Department, World Bank. Retrieve from:

Berge, Z., \& Leary, J. (2006, June 12). Trends and Challenges of eLearning in National and International Agricultural Development. International Journal of Education and Development using ICT [Online], 2(2). Retrieved from: http://ijedict.dec.uwi.edu/viewarticle.php?id=179.

CSL E-Learning Online Archive. (2006, January). http://student.cs.ucc.ie/ xd1. http://www.agr.gc.ca/ren/serv/elearn_e.pdf.

http://www.worldbank.org/wbi/sdruralpoverty/ag_extension1/Materials/additional/Rural_exte nsion.pdf.

Xiaoye, D., Sabin, T. (2007, March). A Theoretical Multimedia Synchronization Framework for E-Learning System. Vol. 10 No. 2 pp 225 - 230.

Xiaoye, D., Sabin, T., Eamon, L. (2005, June). JAS - An E-Learning Tool for Building Multimedia Presentations. IMSCCS'06 Vol. 1 pp $743-746$. 